\section{A não-notícia, um produto do infoentretenimento}

Fabiana Moraes da Silva

\section{Resumo}

Este artigo tem como objetivo sugerir uma nova categorização jornalística: a não-notícia, produto cada vez mais presente em nosso cotidiano. Para isso, estudamos a revista de celebridades Caras, a mais famosa entre as publicações de celebridades do país. Nossa hipótese é que, utilizando alguns conceitos já previstos na Teoria do Jornalismo e da Notícia e subvertendo outros cânones, a mídia cria acontecimentos para se auto- alimentar. Analisar este caso pode nos ajudar a entender a nova realidade midiática. Neste ambiente, as notícias - a não-notícia - é o resultado de um momento em que a mídia não é só um suporte para os eventos que acontecem no mundo: ela os cria por si própria.

Palauras-chave:

Não-notícia, Pseudo-evento, Infoentretenimento, Caras

\section{The no-news, a product of infotainment}

\section{Abstract}

This paper has as main objective to suggest a news' classification which we call non-news, a product strongly present in our lives nowadays. We analyze the most famous celebrity publication in Brazil, a magazine called Caras. Our hypothesis is that, the media creates a phenomenon of self feeding. Weapply some concepts from the News and Journalism theories, and we subvert the cannons. To analyse this case can help us to understand a new mediatic reality. In this environment, the news - the non-news - is a momentary result in which the media does not cover events that take place in the outside world, the media creates the non-news itself by self feeding.

Key words:

Non-news, Pseudo-event, Infoentertainment, Caras magazine 
O que transforma um fato em notícia? O que é um acontecimento real? Feitas diante do caleidoscópio do infoentretenimento, esse um novo paradigma no estudo da comunicação, estas perguntas, já respondidas por alguns teóricos do jornalismo, ganham novos sentidos e, conseqüentemente, novas respostas.

Apesar de bastante teorizado, o conceito de notícia sempre deixou aberturas para interpretações dúbias ou mesmo mostrou-se insuficiente e contraditório ao definir esse fenômeno da cultura de massas. Uma das causas desse fato reside na própria mudança na noção de realidade pela qual vem passando a sociedade nas últimas décadas, mudança essa baseada principalmente, como escreveu Gabler (1999), no desejo de entretenimento.

Para ele, o noticiário se tornou um fluxo constante daquilo que poderíamos chamar de lifies - uma fusão de life e movie, ou seja, vida e filme - inseridos no veículo vida, projetados na tela e na vida e exibidos pela mídia tradicional, cada vez mais dependente do veículo vida (1999:12). Seja no julgamento de O. J. Simpson, na cobertura da morte de Diana, na bomba na repartição em Oklahoma City ou nas aventuras sexuais do ex-presidente Bill Clinton, a mídia se ocupa de casos que se tornam "sucessos de bilheteria".

Para Patterson (2003), à medida que a competição entre organizações noticiosas se intensificou, as notícias modificaram-se, na forma e no conteúdo, no sentido do entretenimento. Segundo ele, é o que o acadêmico e antigo jornalista televisivo Marvin Kalb chama de "as novas notícias" (Kalb, 1998; Frank, 1991; Gamson, 1995). São

\section{O conceito de notícia sempre deixou aberturas para interpretações dúbias ou mesmo mostrou-se insuficiente e contraditório ao definir esse fenômeno da cultura de massas}

elas: o jornalismo centrado no mercado, o infotainment (definição em inglês para infoentretenimento) e as notícias leves. Foi no âmbito dessa luta por audiências que o jornalismo foi se aproximando cada vez mais do que é diversão, criando (ou sofisticando, muitas vezes) uma modalidade informativa que prioriza o espetacular. Talvez um dos grandes fenômenos que sintetizem essa modificação da necessidade da notícia como diversão seja o aparecimento, em meados dos anos 80, nos Estados Unidos, da idéia do infoentretenimento, terminologia que une a idéia de informação e espetáculo num mesmo pacote. De acordo com Albertos (1999), é a notícia como uma modalidade concreta dentro do mundo espetáculo, a idéia de entreter o público simulada dentro do ambiente do jornalismo, que vai se tornando mais carregado de subjetividade.

Essa mescla entre um termo que até então era considerado constituído por "parte objetiva da realidade" e outro cujo objetivo principal é divertir uma platéia resulta, assim, na definição do que hoje seria notícia. A respeito do conceito de infoentretenimento, diz Bertrand:

La info-diversión, o sea, hechos diversos, escándalos, conflictos, desastres; es decir, espectáculos, interesantes ciertamente, llenos de personajes pintorescos que a menudo carecen de importancia, informa muy poco sobre el mundo que nos rodea. ( Bertrand apud Albertos, 1999)

Para Gitlin (2003), para quem as mídias não são apenas representações, mas também promessas, esse campo - transformado em grande palco para gerar e vender sensações - é a grande oferta para os consumidores ansiosos por sentimentos mais palatáveis. 
A mídia, diz ele, é um conduto para um modo de vida que é identificado com a racionalidade, a conquista tecnológica e a busca da riqueza. Mas ela, hoje, desempenha um papel ainda mais poderoso dentro das organizações sociais: algo que chamamos de diversão, conforto, conveniência ou prazer. Boorstin (1992) também percebe que os media foram, cada vez mais, tornandose veículos para a obtenção da satisfação e do prazer social, numa relação que termina, curiosamente, nascendo de uma fonte indefinida: foram as pessoas que inicialmente procuraram satisfação na mídia, ou foi a mídia que procurou criar novas necessidades de satisfação nas pessoas? Diz Boorstin: "Nós esperamos novos heróis todas as temporadas, uma obra-prima literária a cada mês, um espetáculo dramático toda semana, uma sensação rara todas as noites" (1991:3/4. Tradução nossa).

Aliada a todo esse panorama fluido entre o que é informação e o que é entretenimento, está o próprio conceito contraditório do que é notícia e, ainda, acontecimento. Um dos grandes desafios da comunicação é ainda a ausência de uma teoria da notícia elaborada e completa, apesar dos muitos estudos na área, fundamentais para se entender o próprio espectro noticioso atual. Essa ausência, segundo Traquina (2001), manifesta-se na existência de múltiplas "teorias". Com o infoentretenimento hoje como base, estes conceitos mostram-se cada vez mais distantes da realidade do que é produzido e lido nos jornais e revistas. Apesar de atual, o fenômeno que une diversão e informação já tem bases bem definidas em várias teorias noticiosas: na década de 70, autores como Tuchman (1976), Darnton (1975) e Bird e Dardenne (1988) começam a analisar as

notícias como narrativas, observando o jornalista também como um contador de histórias (apud Traquina, 2001:58). Essa percepção foi ainda mais reforçada devido ao boom do novo jornalismo ocorrido nos EUA a partir da década de 60, quando autores como Tom Wolf e Gay Talese começaram a mesclar textos jornalísticos e literatura. As críticas a esses estudos surgiram rapidamente, sobretudo pelo fato de a "verdade" e a "realidade" serem duas das bases mais fervorosamente defendidas pelos profissionais - e mesmo pelos acadêmicos - da época. Diz Tuchman:

\footnotetext{
Dizer que a notícia é uma 'estória' não é de modo nenhum rebaixar a notícia nem acusá-la de ser fictícia. Melhor, alerta-nos para o fato de a notícia, como todos os documentos públicos, ser uma realidade construída possuidora de sua própria validade interna. Os relatos noticiosos, mais uma realidade seletiva do que uma realidade sintética, como acontece na literatura, existem por si sós. Eles são documentos públicos que colocam um mundo à nossa frente (Tuchman apud Traquina, 1976/1993: 262).
}
Foram as pessoas que inicialmente procuraram satisfação na mídia, ou foi a mídia que procurou criar novas necessidades de satisfação nas pessoas?

Autores como Fontcuberta (1993), Tuchman (1983) e Gomis (1991) prevêm em suas teorias da notícia, assim como Alsina, fatores que não estão ligados ao conceito duro de notícia, onde o repórter escreve aquilo que vê fielmente ao que foi observado. A primeira, não obstante, inclui em suas análises as possibilidades de criação - baseada, claramente, num fato ocorrido. A seguir, algumas dessas abordagens: Fontcuberta usa dois conceitos da notícia que fazem parte da idéia do infoentretenimento: as notícias de 
interesse humano e as notícias de criação. A primeira tem o objetivo de atingir a emotividade do leitor, de forma mais sutil ou mais declarada. A lágrima, a voz embargada, o suor no rosto: informações dessa natureza colocadas no contexto de outras notícias, mesmo das consideradas hard news, dão toques, ainda que suaves, de interesse humano aos textos. Para Fontcuberta, esse tipo de notícia está na fronteira entre as notícias diretas e as notícias de criação, já que mesclam a informação mais seca com o estilo narrativo. Já as notícias de criação fazem parte do conceito de periodismo informativo de creación (PIC) - o jornalismo informativo de criação - postulado por Albert Chillón e Sebastián Bernal, ambos da Universidade de Barcelona. É dentro desse tipo de jornalismo, que tem como objetivo entreter o leitor, complementar a informação da notícia direta e incorporar novas formas de narração e linguagem ao jornalismo, que estão inseridas as notícias de criação. De acordo com Fontcuberta, esse tipo de notícia rompe com as estruturas da notícia direta e realiza-se com mais liberdade narrativa, utilizando anedotas, descrições, diálogos, etc.

Das teorias noticiosas que melhor abarcam a idéia da notícia como diversão, talvez a de Gomis seja uma das mais interessantes. Nela, está incluído o conceito das aparições ou presenças eloqüentes. Traço jornalístico que tem muito comentário com pouca inversão (ou mesmo variação no sistema), as aparições, tão caras ao tipo de jornalismo que tem como principal função divertir, são usadas geralmente, segundo Gomis, pelo jornalismo barato, gratuito, com bom rendimento ("hace hablar la gente"). Essas aparições, que não poupam exatamente quem será enfocado, seja um político, um atleta,

\section{A lágrima, a voz embargada, 0 suor no rosto: informações dessa natureza colocadas no contexto de outras notícias, mesmo das consideradas hard news, dão toques, ainda que suaves, de interesse humano aos textos}

uma modelo ou uma atriz de novela, basta que seja famoso, são diversas vezes pseudoeventos. Basta que o personagem conhecido diga algo, mesmo que esse algo não contenha nada relevante. Elas, ao contrário dos resultados, que servem como o esqueleto da notícia, lhe dão cor e chamam atenção. "É o comentário transformado em notícia, a palavra considerada como acontecimento, a subjetividade acolhida com atenção e respeito e difundida amplamente" (1991:126).

Outra característica que transforma um fato em notícia, para o autor, são os deslocamentos, notícias geradas a partir de agrupamentos significativos, mudanças de lugar, reuniões de pessoas, alterações de grupos ou costumes (coincidem com aparições ou completam-se jornalisticamente com elas). Podem ser protestos, seqüestros, mudança de partido político, assembléia, greves, reuniões de chefes de Estado e até mesmo a previsão do tempo, uma espécie de deslocamento continuado. "É uma trajetória intencional que significa ou quer dizer algo", ou seja, traços ou perfil de atos que se convertem em um fator noticioso. Esses descolamentos, aliás, oferecem inúmeras aparições, sendo também grandes geradores de pseudo-eventos. "Alguém ou algo há se movido, e essa trajetória tem um sentido ou significação" (1991:136).

Finalmente, Tuchman nos oferece o conceito de notícias brandas (soft news). As notícias leves são lidas em cadernos dominicais, em revistas voltadas para diversos públicos (e não apenas para o feminino), em noticiários dos horários nobres e ainda mais fortemente em telejornais matutinos, que produzem matérias sobre receitas gastronômicas, roteiros turísticos, histórias de vida, etc. Os informadores dizem que a 
notícia dura se refere à informação que teriam que ter as pessoas para serem cidadãos informados, e as notícias brandas se referem a fraquezas humanas e à 'textura de nossa vida humana' (Mott apud Alsina, 1996).

\section{Uma sociedade acontecedora}

Apesar de nem todos os termos serem compartilhados pelos teóricos, há um fenômeno específico que surge em diversas definições sobre o maior produto do jornalismo: é a necessidade do acontecimento, fundamento do tecido noticioso. Para que exista notícia, é preciso que exista acontecimento, um feito que irrompe no sistema social e que provoca variação no sistema (Alsina, 1996: 96). Para Gomis, o acontecimento seria "qualquer coisa que ocorre: algo que se sucede em alguma parte. Pode ser uma frase, gesto, ato físico, um conjunto de palavras, gestos ou atos que o observador interpreta como uma unidade de sentido" (1991: 51). Numa sociedade cada vez mais "acontecedora" (Tudescq apud Alsina, 1996), porém, onde a necessidade de novos eventos é quase um dogma gerado pelo próprio campo midiático, o uso do pseudo-acontecimento é legítimo para produzir notícias classificadas como verdadeiras, ou, num termo mais preciso, já que a separação entre verdade e ficção torna-se cada vez mais fluida, espontânea. O termo pseudo-evento foi cunhado primeiramente por Boorstin (1992), que analisou a fabricação de eventos nos Estados Unidos após a década de 50 . Até o início do século XIX, a sociedade norte-americana contentava-se em ler notícias publicadas com maior espaço de tempo, e estas vinham de acordo com a geração espontânea de fatos. Se não houvesse nada intrigante ou espantoso acontecendo, não era falha do repórter. Ele não poderia reportar

\author{
O uso do \\ pseudo- \\ acontecimento \\ tornou-se \\ legítimo para \\ produzir notícias \\ classificadas como \\ verdadeiras, já \\ que a separação \\ entre verdade e \\ ficção é cada vez \\ mais fluida
}

algo que não existia (1992:7). Os pseudoeventos possuem características próprias, algumas delas se relacionando diretamente com as outras:

1- Não são espontâneos, e sim planejados, plantados ou incitados. Jamais seriam possíveis num terremoto ou num acidente de trem, e sim numa entrevista.

2- São plantados para imediatamente serem reportados e reproduzidos, e essa reprodução é organizada de forma conveniente para ser reportada pela mídia. A grande pergunta "isso é real?" é menos importante do que "vale a pena ser publicado?"

3- Sua relação com o conceito de realidade é ambígua. Na verdade, o interesse pelo material cresce à medida que ele é de fato ambíguo.

4- Geralmente, se auto-realiza ao cumprir sua própria profecia. Tem o mesmo conceito que um fait divers: seu sentido termina nele mesmo.

Partimos do princípio de que toda nãonotícia está baseada em um pseudo-evento: são nos acontecimentos criados justamente para surgirem na mídia que observamos notas, reportagens ou mesmo matérias que não necessariamente precisam seguir os preceitos do jornalismo cânone. Nelas, a produção cede lugar ao conceito de espontaneidade ou mesmo de "verdade", este há tempos deixado de lado quando falamos de semanários como a Caras, onde a ambigüidade é muitas vezes o grande teor do que está sendo publicado. De acordo com Bagdikian (apud Gomis), "o pseudo-evento se converteu em um 
instrumento racional e necessário”. Já para o próprio Gomis, os acontecimentos, verdadeiros ou falsos, são, primeiramente, necessidades técnicas (1991:69). A não-notícia, categorização proposta por este trabalho, é um fenômeno previsto dentro da própria teoria da notícia conforme a análise de diversos autores (Gomis, 1991; Cornu, 1994; Alsina, 1996; Jorge Pedro Sousa, 2003; Boorstin, 1992; Moles e Bagdikian apud Alsina, 1996), que identificam diferentes maneiras (não-acontecimento, pseudo-evento, antiacontecimento). Neste artigo, estudaremos esse fenômeno especificamente no contexto da produção do material jornalístico publicado numa revista de celebridades, a Caras, que traz, segundo nosso ponto de vista, não-notícias em suas edições semanais de grande repercussão nacional. Uma não-notícia tem características semelhantes àquelas vistas no campo do jornalismo dito objetivo, ainda cânone, no qual se devem seguir diversos dos valores-notícia. A existência das notícias baseadas em eventos criados também foi analisada por Cornu (1994), que pede uma apreciação crítica da produção do notável pelos media. Ele define esses fatos plantados e sem ressonância social como antiacontecimento:

Fatos de uma total futilidade ou com interesse limitado a um pequeníssimo número de pessoas são levados ao conhecimento do público, só porque valorizam as atividades de uma instituição, de um político, de uma empresa da praça (...) Tudo isso constitui aquilo que chamamos de antiacontecimentos (Cornu, 1994: 295).

\section{A não-notícia em Caras}

O fenômeno, conceito proposto por este artigo, forma-se a partir da produção noticiosa baseada em acontecimentos criados. Ela,
A não-notícia é um produto que a própria mídia cria para se alimentar, falar de si mesma e produzir outras não-notícias porém, vai mais além do pseudo-evento de Boorstin, que prevê a criação de fatos voltados para alimentar a mídia. A não-notícia é um produto que a própria mídia cria para se alimentar, falar de si mesma e produzir outras não-notícias. A não-notícia é, ainda assim, uma categoria da própria mídia. Neste artigo, propomos seis exemplos da não-notícia, todos eles retirados a partir de um estudo sobre a revista Caras: a publinotícia; o amor e a não-notícia nos ambientes criados; auto-notícias; a não-notícia e a aparição; a entrevista criada e, finalmente, a ambigüidade. É necessário explicar que todas elas se relacionam entre si, suas fronteiras são fluidas e muitas vezes uma mesma não-notícia apresenta três dessas características noticiosas (no caso, seria nosso umbral de não-noticiabilidade, evocando o conceito de Galtung e Ruge). A cada uma das propostas, segue-se um exemplo noticioso em Caras.

\section{(a) Publinotícias}

O que Caras nos mostra de diferente em relação à tradicional relação entre a publicidade e o jornalismo, cujas fronteiras são marcadas e há uma definição dos dois papéis - o de informar e o de vender? Observando diversas matérias da revista, percebemos que não há nenhuma determinação traçada entre o que está sendo informado ou divulgado: patrocinadores e anunciantes estão colocados em meio às reportagens e são fotografados da mesma forma que as celebridades usualmente mostradas. Jóias, celulares e carros ganham a mesma atenção que a atriz famosa; os representantes das marcas que apóiam os eventos criados pela revista opinam nas matérias, mostram suas impressões ao mesmo tempo que determinado famoso fala sobre o produto vendido. 
É a própria existência do anunciante em eventos ou edições específicas que vai determinar a construção de uma não-notícia em Caras.

Exemplo: Na edição 582 (ano 11, n.53, 31/12/2004), Caras traz uma ceia na casa do ator Rodrigo Faro e da modelo Vera Viel. Ao lado do título, uma legenda diz: Surpresa: o galã é recebido pela mulher com jantar oriental servido em baixela Tramontina.

Primeiramente, Caras nos informa que o jantar foi uma surpresa, enquanto, mais adiante, informa que o jantar teve produção de um bufê carioca. O casal também preparou-se, vestindo branco, para ilustrar a última edição do ano da revista. O fato, criado para servir como matéria, tem apoio da Tramontina, que ainda aparece em outra legenda da publinotícia: "Rodrigo serve champanhe para Vera e eles brindam. Carina Chaves, da empresa Jantar a 2, cuidou de tudo: da decoração ao menu, servido em práticas baixelas Tramontina”.

\section{(b) A não-notícia e a felicidade}

A construção da felicidade de um casal (Eliana e Eduardo Guedes) é um dos exemplos da não-notícia baseada no mito felicidade presente em Caras. Durante algumas edições, a relação do casal foi sendo construída de maneira que sugeria que a própria revista era uma espécie de madrinha. No castelo na França, ele a pediu em casamento e ela aceitou (e esse momento é a capa de uma das edições do semanário). Depois, a revista "segue" os noivos em vários momentos de romance e descanso. Finalmente, em uma edição especial, Caras faz a cobertura, com fotos exclusivas, do casamento de Eliana e Eduardo. E também entrevista o casal antes que este siga para a lua-de-mel.

\section{Caras produz uma não-notícia não quando publica o casamento de uma celebridade, um fato em si, mas quando sugere que este casamento nasceu em um convite "espontâneo" feito no Vale do Loire}

Caras consegue, assim, organizar a longo prazo as matérias que serão publicadas, garante material exclusivo e, mais importante ainda, tem dois olimpianos que trazem em si os conceitos míticos de beleza e sucesso. Caras produz uma não-notícia não quando publica o casamento de uma celebridade, um fato em si, mas quando sugere que este casamento nasceu em um convite "espontâneo" feito no Vale do Loire. Exemplo: A edição 569, ano 11, n. . 40, 1/10/2004, traz na capa o empresário Eduardo Guedes e a apresentadora Eliana anunciando que irão se casar em pleno Castelo de Caras. A matéria, produzida durante uma viagem de vários famosos e patrocinada por empresas como a joalheria H.Stern, traz na chamada de capa "Eliana anuncia no Castelo de Caras que se casa em 10 de dezembro". Como não poderia deixar de ser, esse amor, que se hiper-realiza nas páginas de Caras, deverá então ser acompanhado pelos não-olimpianos desejosos de uma felicidade perfeita - por isso entendemos ser importante acompanhar a trajetória do amor de Eliana e Eduardo até as bodas.

\section{(c) Auto-noticias}

Numa análise rápida de algumas edições de Caras, percebe-se que a própria revista é uma das grandes celebridades publicadas nas suas páginas (exemplo que já se percebe no exemplo do anúncio do casamento da apresentadora Eliana no castelo). Esse é um dos motivos da existência de ambientes como a Ilha e o Castelo de Caras, espaços olimpianos por excelência: neles, Caras se mostra e se auto-realiza, servindo como uma espécie de anfitriã que recebe vips e personalidades em sua casa, fazendo sempre questão de abrir as portas. Essa característica - um meio jornalístico de usar a si próprio como um acontecimento - não é recente e foi brevemente vista por Alsina (1996), 
que cita um artigo do periódico L'Événement (1848), do qual participava Victor Hugo:

Se, por impossibilidade, o acontecimento nos falhasse alguma vez, nós reuniríamos no mesmo número, e como uma constelação deslumbrante, todos os nomes ilustres que estrelam nossa redação, e tentaríamos este dia em que nosso jornal fosse ele mesmo o acontecimento (1996: 87).

Exemplo: Na edição 587, ano 12, n. $^{\circ}$ 5, 4/2/2005, vê-se uma não-matéria sobre o lounge que a revista montou durante uma semana de moda nacional. O ambiente é o próprio motivo da matéria e a ele é dedicado o título "Lounge Caras é point no mês da moda brasileira". Os diversos famosos que passam pelo espaço são fotografados ora lendo a revista ou um jornal parceiro do semanário.

\section{(d) Aparições}

Criando seus acontecimentos para alimentar a si mesma, Caras deixa de se utilizar de uma das premissas do que transforma um fato em notícia - as aparições previstas em Gomis (1992) e Martini (2000), por exemplo. Seus personagens, na maioria das vezes, não se inserem espontaneamente no espaço midiático. Têm aparições programadas, e, portanto, são exemplos de pseudo-acontecimentos. Para Gomis, a aparição é geralmente jornalismo barato com o qual se obtém um bom rendimento. Segundo ele, muitas dessas aparições constituem-se em negociações entre revistas e entrevistados. Há personagens que pedem um preço por uma aparição, como se aparecer na mídia fosse parecido a representar um papel em um
Seus

personagens

não se inserem

espontaneamente

no espaço midiático.

Têm aparições

programadas,

e, portanto,

são exemplos

de pseudo-

acontecimentos cenário. Isso acontece especialmente no caso das revistas semanais que se nutrem de personagens e vidas. O pseudo-evento pode alcançar a vida familiar, converter-se em um relacionamento ou em divórcio, um nascimento pode tratar-se de um pseudo-evento (Gomis, 1992:131). Se as presenças eloqüentes fazem parte dos valores-notícia previstos pela teoria do jornalismo e são usadas nos acontecimentos previstos de Caras, o que dizer das diversas não-notícias publicadas no semanário sobre o cotidiano de personagens que não têm fama ou qualquer reconhecimento público? Neste artigo, utilizamos uma nota da edição 569 (ano 11, número 40, 1/10/2004) onde Caras publica o aniversário da pequena Annabela, de dois anos, filha dos donos do castelo turístico que a revista denomina de "Castelo de Caras". Mesmo sendo desconhecida, filha de um casal também desconhecido pelos brasileiros, a garota ganha espaço na revista por estar inserida no ambiente do castelo.

\section{(e) A entrevista criada}

As revistas de celebridades também se baseiam em duas das categorias noticiosas defendidas por Gomis (1991) vistas neste trabalho: as aparições, sobre as quais falamos na categorização anterior, e os deslocamentos, fatos anunciados e previstos, facilmente cobertos pela mídia por seu caráter espetacular e programado, o que facilita a organização da temporalidade dos meios. Esses deslocamentos têm uma organização por trás - já que geralmente são feitos para produzir ressonância na mídia - e podem ser facilmente, ao ser agregados às aparições, produtores de pseudo-eventos. "Mobilizam muita gente, o que lhes dá um ar vistoso e espetacular. Asseguram também a presença de desconhecidos nos meios" (1991:142). Unidas, essas duas categorias são facilmente vistas em um dos re- 
cursos jornalísticos mais comuns para identificar a não-notícia em Caras: a entrevista. É levando famosos e vips para locais como Ilha, Castelo ou mesmo outros ambientes (como os lounges de Caras nas semanas de moda) que o semanário consegue garantir tanto a aparição quanto o deslocamento desses olimpianos. Feito isso, esses personagens são entrevistados e suas falas são transformadas em acontecimento pela revista.

Ao levar diversas vezes pessoas cuja aparição não produz nenhum sentido no espaço público, a revista termina não seguindo a própria lógica instituída por Gomis: para ele, os deslocamentos só ganham sentido quando o personagem que se desloca é conhecido, relevante, ou o número de pessoas reunidas é não habitual, surpreendente. No exemplo a seguir, percebemos um dos traços mais marcantes no semanário e sua produção de não-notícia: a entrevista realizada dentro do próprio ambiente Caras. Na edição 586, ano 12, n. ${ }^{\circ}$ 4, 28/1/2005, a atriz Leona Cavalli surge na piscina da Ilha de Caras numa não-entrevista na qual fala sobre projetos futuros. A fama da atriz por si só já a encaixaria num "artigo noticioso". O que se tem aqui, porém, é a produção do semanário em realizar uma entrevista na qual a própria ilha é um segundo personagem. Aliado a isso, está o fato de a matéria trazer em suas fotografias marcas dos patrocinadores que patrocinaram o verão Caras daquele ano.

\section{(f) A não-notícia e a ambigüidade}

Uma das características mais comuns dos pseudo-eventos é a presença da ambigüidade: o "deve ser", a celebridade que, fotografada ao lado de um novo par, argumenta: "Somos apenas bons amigos", o silêncio de um famoso diante de algum suposto escândalo. Não esclarecido, o não-acontecimento torna-se cada vez mais comentado, alimentando assim uma série de suposições e, conseqüentemente, novos pseudo-eventos. Esse fenômeno foi identificado por Boorstin (1992), que vê na presença da ambigüidade um dos fatores mais comuns na construção de um acontecimento criado. Os pseudo-eventos se alimentam da ambigüidade para produzir ressonância no campo midiático, gerando comentários e garantindo assim sua presença nos meios de informação. Diz Boorstin sobre essa característica do não-acontecimento:

\begin{abstract}
Sua relação com a realidade é ambígua: seu interesse é maior à medida que ele é mais ambíguo. No pseudo-evento, a pergunta "o que isso quer dizer?" ganha novo sentido. "Enquanto as notícias que interessam em um acidente de trem são o que aconteceu e suas reais conseqüências, o interesse em uma entrevista é sempre o que poderia acontecer e quais os possíveis motivos (1992:11. Grifo nosso).
\end{abstract}

A ambiguidade é um dos assuntos mais caros às revistas de celebridade: a partir da dúvida, pode-se criar boatos, comentários e, por fim, notícias. No exemplo a seguir que vemos em Caras, porém, a falta de acesso a um acontecimento envolvendo duas celebridades nacionais (o casamento de Ronaldinho e Daniela Ciccareli) terminou por produzir uma não-matéria repleta de suposições publicadas como reais. O próprio texto, onde o uso de "estaria", "deveria" e "deve ter" são constantes, mostra a extrema ambigüidade de um fato publicado com destaque pelo semanário:

Pela programação, a noite começaria com uma bênção do padre Antônio Maria (59). Com trajes do estilista italiano Valentino (72) - o da noiva, um vestido de cetim e tule superfino, estilo camisola, com renda nas laterais e nos punhos, estimado em 200000 reais, e o do noivo, um fra-
Não esclarecido, 0 não-anteciment -se cada vez alimentando assim uma série de suposições e, conseqüentemente, novos pseudo- eventos


que moderno que deve ter custado por volta de 40000 reais -, Daniela e Ronaldo se encontrariam com seus convidados em um anexo do castelo (...) Ainda assim, estava previsto que a decoração, do florista Vic Meirelles (39), usaria tulipas brancas e folhagens para a sala da bênção e flores vermelhas para o jantar. O bolo seria uma escultura de chocolate decorada com flores de açúcar vermelhas. Um toque brasileiro estaria no bar, servindo caipirinhas (...).

Baseados nesses breves exemplos, cabe a pergunta: os mass media, campo autônomo que produz os próprios temas, são um reflexo de nossa necessidade de diversão? Preferimos hoje ser entretidos a ser informados? Apesar de concordarem que os meios de comunicação não sejam responsáveis por si só pela "invasão" midiática na vida diária, os defensores da atual barragem das mídias, diz Gitlin, costumam concordar que ela chega a ser uma distração do fardo da vida industrializada. Vale lembrar que ela é mesmo celebrada, a partir de sua capacidade de distrair, como um remédio valioso e necessário.

\section{Sobre a autora}

Fabiana Moraes da Silva, Mestre em Comunicação pela UFPE, doutoranda do programa de pós-graduação em Sociologia da UFPE. email:fabimoraes@gmail.com

\section{Referências}

ALSINA, Miguel Rodrigo. La construcción de la noticia. Barcelona, Buenos Aires, México: Paidós, 1996. BOORSTIN, Daniel. The image: a guide of pseudoevents in America. New York: Vintage Books, 1992. CORNU, Daniel. Jornalismo e verdade. Lisboa: Instituto Piaget, 1994.

ECO, Umberto. Viagem na irrealidade cotidiana. Rio de Janeiro: Nova Fronteira, 1984.
FONTCUBERTA, Mar de. La noticia: pistas para percibir el mundo. Barcelona: Paidós, 1993.

GABLER, Neal. Vida, o filme. São Paulo: Companhia das Letras, 1999.

GITLIN, Todd. Mídias sem limite: como a torrente de imagens e sons domina nossas vidas. Rio de Janeiro: Civilização Brasileira, 2001.

GOMIS, Lorenzo. Teoría del periodismo: como se forma el presente. Barcelona: Paidós, 1991.

MARTINI, Stella. Periodismo, notícia e noticiabilidade. Buenos Aires: Grupo Editorial Norma, 2000.

SOUSA, Jorge Pedro. As notícias e os seus efeitos: as "teorias" do jornalismo e dos efeitos sociais dos media jornalísticos. Lisboa: MinervaCoimbra, 2000.

TRAQUINA, Nelson. Teorias do jornalismo - a tribo jornalística: uma comunidade interpretativa transacional. Florianópolis: Insular, 2005. $2 \mathrm{v}$.

$O$ estudo do jornalismo no século $X X$.

São Leopoldo: Unisinos, 2001.

TUCHMAN, Gaye. La producción de la noticia: estudio sobre la construcción de la realidad. Barcelona: Gili, 1983.

\section{Referências Webgráficas}

ALBERTOS, José Luiz M. El periodismo en el siglo XXI: Mas allá del rumor y por encima del caos. In Estudios sobre el mensaje periodístico. 1999. Disponível em http://www.ucm.es/info/emp/Numer_05/53-Estu/5-3-1.htm.

DEBORD, Guy. A sociedade do espetáculo. Disponível em: http://www.geocities.com/Paris/Rue/5214/debord.htm. Acesso em: 03 mai. 2004.

PATTERSON, Thomas E. Tendências do jornalismo contemporâneo: estarão as notícias leves e o jornalismo crítico a enfraquecer a democracia? In: Media \& Jornalismo, vol. 1, n. ${ }^{\circ}$ 2, p. 19-47, abr. 2003. Disponível em: http://revcom.portcom.intercom.org.br/scielo. php. ISSN 1645-5681. Acesso em: 09 jul. 2004.

Recebido em 3 de março de 2008 Aprovado em 28 de abril de 2008

\section{Estudos em Jornalismo e Mídia}

Ano V № 1 - 1o semestre de 2008 